\title{
Investigating the relationships between social capital, chronic health conditions and health status among Australian adults: findings from an Australian national cohort survey
}

Jeong Kyu Lee ${ }^{1 *}$, Lavinia Lin ${ }^{1}$ and Christopher Magee ${ }^{2}$

\begin{abstract}
Background: Social capital is a collective attribute of communities that determines health and well-being of populations. The collective resources in a high social capital community have been reported to result in better health outcomes. While evidence supports the links between social capital and various health outcomes, it is not clear about underlying mechanisms connecting multiple dimensions of social capital to health.

Methods: Using the two-wave data from a nationally representative cohort study of Australian adults $(N=16,637)$, this study examined the effects of two dimensions of social capital (i.e., structural and cognitive social capital) on physical and mental health in the Australian adult population. Based on prior literature and theoretical reasoning, it was anticipated that the structural and cognitive social capital would influence self-assessed health status (physical and mental health). Additionally, these two dimensions of social capital were hypothesized to moderate the relationships between chronic health conditions and these two aspects of health status.

Results: Analyses showed that the effects of chronic health conditions on mental health status were moderated by the structural social capital $(\beta=.652, S E=.249, p=.009)$. Additionally, it was found that perceived community cohesion was predictive of mental health $(\beta=.295, S E=.103, p=.004)$. Our analysis also indicated that perceptions of disadvantaged neighbourhood environment contributed to poorer mental health status $(\beta=-.461, S E=.144$, $p=.001)$. However, none of the social capital variables significantly predicted physical health status.

Conclusions: Findings suggest that the structural dimension of social capital would function as a buffer against the malicious effects of chronic health conditions, impairments and disabilities. Specifically, community participation (structural social capital) is indispensable to develop an effective community-based program to improve health and well-being of those with chronic health conditions or disabilities, as increasing active participation may generate beneficial effects in this vulnerable population. Subjective perceptions about communities can also play an important role in improving better health outcomes. Further research is needed to examine underlying mechanisms linking the multiple dimensions of social capital to health outcomes among individuals who are vulnerable to external stressors.
\end{abstract}

Keywords: Social capital, Health status, Chronic Health conditions, Cohort data

\footnotetext{
* Correspondence: ephljk@nus.edu.sg

'Saw Swee Hock School of Public Health, National University of Singapore

and National University Health System, Singapore, Singapore

Full list of author information is available at the end of the article
}

(c) The Author(s). 2020 Open Access This article is distributed under the terms of the Creative Commons Attribution 4.0 International License (http://creativecommons.org/licenses/by/4.0/), which permits unrestricted use, distribution, and reproduction in any medium, provided you give appropriate credit to the original author(s) and the source, provide a link to the Creative Commons license, and indicate if changes were made. The Creative Commons Public Domain Dedication waiver (http://creativecommons.org/publicdomain/zero/1.0/) applies to the data made available in this article, unless otherwise stated. 


\section{Background}

The impact of social environmental factors on health and well-being has been widely studied over decades [1]. Since individuals' behaviours and their social relations are embedded in neighbourhoods and communities, the concept of social capital provides a valuable conceptual perspective to understand how social environment influences health outcomes and behaviours [2, 3]. Social capital is an important determinant of health and overall wellbeing [4]. Despite increasing acknowledgement, social capital suffers from a lack of consensus on its operationalization and measurement as the definitions and concepts are malleable depending on different contexts [5].

In the fields of public health and social epidemiology, Robert Putnam's definition of social capital has been widely utilised [6]. Putnam conceived of social capital as a collective attribute of communities and societies, and it is commonly characterised by social cohesion, trust, norms of reciprocity and density of membership [7]. Building on his conceptualization [8-11], the current study focused on two distinct dimensions of social capital: structural (i.e., what people do) and cognitive (i.e., what people feel) components. The structural component relates to the composition, extent and intensity of participation in the community, and memberships of social groups and organisations [11-13]. The cognitive component of social capital, on the other hand, refers to subjective perceptions about the community resulting from participation [2, 14]. In this study, the cognitive component was operationalised by perceptions of community cohesion encompassing neighbourhood trust and belongingness [14, 15].

\section{Social capital and Health}

Numerous studies have found significant associations between social capital and various health behaviours and outcomes, such as self-assessed health [16-18], mental health and well-being [12, 19], psychological distress [13], cardiovascular and cancer mortality [20], vegetable and fruit consumption [21], physical activity [22], and smoking cessation [23-25]. It has been suggested that social capital can influence health through various mechanisms [2]. Community participation (structural social capital) is known to improve health, as it acts as a conduit for the transmission of knowledge [26]. It can also strengthen behavioural norms or adoption of related behaviours [27, 28]. Subjective perceptions about communities (cognitive social capital) also play an important role in developing and maintaining positive health status [29]. One explanation is that neighbours and other members of the community could act as an important source of trust and support if the community is cohesive, building strong connections among the community members [30, 31]. A recent study reinforced this, finding that neighbourhood cohesion is associated with an increased likelihood of preventive healthcare use and accessibility [32].

Whereas social capital and other community resources (e.g., social support) facilitate better health outcomes, there are some neighbourhood characteristics worsening community health and well-being. Previous studies have suggested that perceived neighbourhood climate such as violence, noise, traffic, and vandalism, may have a negative impact on health and contribute to serious chronic conditions [33, 34]. Hence, this study also looked into the influence of perceptions about neighbourhood social climate (e.g., noise, violence, burglary and theft), in addition to the effects of social capital on health status.

\section{Chronic Health conditions in Australia}

Chronic health conditions including impairments and disabilities are an emerging public health concern in Australia. Approximately half of the population reported that they have at least one prominent chronic conditions (e.g., arthritis, asthma, back pain, cancer, cardiovascular disease, chronic obstructive pulmonary disease, diabetes or mental health conditions), and nearly a quarter of all Australian (23\%) and $60 \%$ of those aged over 65 years had two or more chronic conditions [35]. The prevalence of comorbidities is apparently increasing in Australia due to the older age of the population [36, 37]. Those with chronic health conditions are associated with poor health outcomes that may result in lower quality of life, functional decline, and shorter life expectancy [38, 39]. Some risk factors for chronic conditions include behavioural determinants, such as alcohol use, smoking and poor nutrition and diet, as well as social and economic determinants, which influence individual decisions about their lifestyle [35]. However, it is unclear whether social capital can be a buffer to the negative effect of chronic health conditions including impairments and disabilities.

In addition to the direct effects of social capital, evidence suggests that social capital can buffer against potentially negative consequences of various strains such as poverty, job loss, and retirement $[40,41]$, and negative influence of external stressors on health and related outcomes [42, 43]. In particular, Anwar and colleagues have recently explored a modifying role of social capital in the longitudinal effect of disability onset on mental health using a sophisticated analytic technique. Their findings showed that social capital was beneficial for individuals who had poorer mental health status before their acquisition of disability [44]. With all these evidence, it is reasonable to anticipate that social capital would buffer the influence of chronic health conditions (including impairments and disabilities) on health status (physical and mental health). Challenges lie in linking the concept of 
social capital to chronic health conditions that continues to strain the economies of many countries. By using the concept of social capital, the underlying problem surrounding the prevention and treatment of hypertension and diabetes, for instance can be better understood [45-47].

The current study, therefore, extended previous research by treating the multiple dimensions of social capital as potential moderators on the relationship between chronic health conditions and health status (physical health and mental health) in the Australia adult population. Using a nationally representative cohort data, this study aimed to: 1) examine the effects of the structural and cognitive components of social capital on selfreported physical and mental health status among Australian adults (i.e., direct effect hypothesis); and 2) assess whether the two components of social capital moderate the relationship between chronic health conditions and their health status (i.e., buffering effect hypothesis).

\section{Methods}

This study utilised data from the Household, Income and Labour Dynamics in Australia (HILDA) Survey, a nationally representative longitudinal panel survey of Australian households established in 2001 [48]. Study samples were limited to adults aged 18 years and older $(N=16,637)$. The data were collected from Waves 14 and 15 (July 2014 to Feb 2016), which are referred to as Time 1 and Time 2 respectively in this paper.

The survey is administered annually using a combination of face-to-face interviews and self-completion questionnaire to collect information on social, demographic, health and economic conditions $[49,50]$. The sampling unit of the HILDA Survey is household, following the definition of the Australian Bureau of Statistics (ABS). Detailed information about the HILDA methodology can be found at https://melbourneinstitute. unimelb.edu.au/hilda/for-data-users/user-manuals. The National University of Singapore's Institutional Review Board exempted the study from ethics review as the data were de-identified by the Melbourne Institute and the HILDA operations team.

\section{Measures}

\section{Structural social capital (Time 1)}

Items measuring levels of community participation were derived from the Australian Community Participation Questionnaire, which has been validated in previous report [15]. Following Berry and Welsh's approach [12], a seven-item measure was used to assess individual levels of participation. These items include: 1 ) volunteering to work on boards or committees; 2) attending religious services; 3) organizing community activities; 4) getting involved in political activities; 5) attending community events; 6) giving money to charity; and 7) getting in touch with a local politician or councilor. The intensity of structural social capital were assessed using a sixpoint scale ranging from 1 (never) to 6 (very often). A higher mean score indicated a greater level of community participation. Cronbach's alpha coefficient for the structural social capital measure was 0.75 .

\section{Cognitive social capital (Time 1)}

Perceptions of community cohesion were assessed using a five-item measure rated on a seven-point ranging from 1 (strongly disagree) to 7 (strongly agree) [15]. Items include: "This is a close-knit neighbourhood," "People around here are willing to help their neighbours," "People in this neighbourhood can be trusted," "People in this neighbourhood generally do not get along with each other," and "People in this neighbourhood generally do not share the same values." The last two items were reverse-coded before computing an average score value. A higher mean score indicated stronger perceptions of cohesion. Cronbach's alpha coefficient for this measure was 0.78 .

\section{Neighbourhood social climate (Time 1)}

Neighbourhood social climate were assessed using an eight-item measure on a five-point scale ranging from 1 (never happen) to 5 (very common) [51]. The neighbourhood characteristics included: 1) traffic noise, 2) noise from airplanes, trains, industry, 3) homes and gardens in bad condition, 4) rubbish and littering lying around, 5) teenagers handing around on the street, 6) people being hostile and aggressive, 7) vandalism and deliberate damage to property, and 8) burglary and theft. A higher mean score indicated a poorer quality of neighbourhood social environment. Cronbach's alpha for the measure was 0.86 .

\section{Health status (Times 1 and 2)}

Physical and mental health status (primary outcomes of the study) were evaluated at Times 1 and 2 using the Short-Form Health Survey (SF-36) scale, which is widely used to assess health and functioning in both clinical and non-clinical samples [52, 53]. This scale consists of 36 items to calculate eight subscales of health status: physical functioning, role-physical, bodily pain, general health, vitality, social functioning, role-emotional, and mental health. Following the recommendation by the SF-36 Survey designers [53], we computed the normbased scoring of two component summary measures: Physical Component Score (PCS) and Mental Component Score (MCS). All eight subscales were first standardized using a linear transformation. The four subscales (physical functioning, role-physical, bodily pain, general health) and the other four subscales (vitality, social functioning, role-emotional, mental health) 
were then added up to form the two summary scores for physical and mental health status: PCS and MCS. We produced the two summary scores using the Australian population norms for the transformed scores, which were derived from the Australian National Health Survey [54]. Higher scores of the summary measures indicated better health status in the two domains of health - physical health and mental health.

\section{Chronic health conditions, impairments, and disabilities (Time 1)}

Participants were asked to report whether they had any of the following long-term health condition, impairment or disability restricting their everyday activities for 6 months or more. Conditions included: 1) sight problems, 2) hearing problems, 3) speech problems, 4) black outs, fits or loss of consciousness, 5) difficulty of learning/understanding, 6) limited use of arms or fingers, 7) difficulty gripping things, 8) limited use of feet or legs, 9) nervous or emotional condition, 10) any condition restring physical activity or work, 11) any disfigurement or deformity, 12) any mental illness, shortness of breath, 13) chronic or recurring pain, long-term effects as a result of head injury stroke, or other brain damage, 14) long-term condition or alignment still restrictive after being treated, and 15) other long-term conditions such as arthritis, asthma, heart disease, Alzheimer's disease and dementia. A show card listing examples of chronic health conditions were presented as a prompt for participants. A dichotomised variable was constructed to identify those reported of chronic health conditions, impairments and disabilities in the past 6 months and those who did not report any health conditions.

\section{Lifestyle related factors (Time 1)}

Smoking consumption, drinking consumption, physical activity, and body mass index (BMI) were included. Smoking and drinking consumption were dichotomised as "yes" and "no" to identify participants' current status of smoking and drinking consumption. Levels of physical activity were assessed using an eight-point scale (0-7). They were recoded into four categories: None, 1-2 times, 3-6 times, and Every day. BMI was calculated based on participants' self-reported heights and weights, and those who provided insufficient or implausible information on their heights and weights were excluded from the calculation. Following the Australian Bureau of Statistics' criteria [55], we recoded the BMI data into four categories: underweight $(\mathrm{BMI}<18.5)$, normal weight (18.5-24.9), overweight (BMI 25-29.9), and obese $(\mathrm{BMI} \geq 30)$.

\section{Socio-demographic characteristics (Time 1)}

The following socio-demographics were included: 1) age range (recoded as " 18 to 24, ," 25 to 44 ," " 45 to 64 ," "65 and above"), 2) gender (male vs. female), 3) educational attainment (recoded as "bachelor degree or above," "polytechnic diploma and certificate," "year 12," "year 11 or less"), and 4) country of birth ("Australia-born" vs. "foreign-born").

\section{Statistical analysis}

Data were analysed using Mplus Version 6.11 [56]. Statistical analyses (bivariate and multivariate) were performed to assess relationships between sociodemographics, social capital and health status among adults with and without chronic health condition, impairment or disability. Prior to regression analyses, preliminary tests for normality and multicollinearity were conducted. Results showed that data met the assumptions of normality and the scores of the variance inflation factor (VIF) ranged from 1.05 to 3.36, indicating low to moderate correlations among the variables used in the regression models.

Two sets of multiple linear regression models (main analysis) were built to assess the effects of social capital on the two summary measures of SF-36 (Model I predicting physical health status [PCS] and Model II predicting mental health status [MCS]), controlling for socio-demographic characteristics, lifestyle factors and the two summary scores at baseline. All the parameters were estimated using the maximum likelihood estimation method with robust standard errors. The analyses yielded adjusted regression weights $(\beta)$ with standard errors $(S E)$. The two regression analyses (Models I and II) were performed by regressing the two outcome variables - PCS and MCS on potential predictor variables, including the two components of social capital (i.e., community participation and perceived cohesion). The two summary scores, PCS and MCS at Time 2, were included in the regression models as the outcome variables and the two summary scores at Time 1 were used as covariates to adjust change over time. To test the moderation effects of the two dimensions of social capital on the relationship between chronic health conditions and health status, two interaction terms (community participation $\times$ chronic health conditions and perceived cohesion $\times$ chronic health conditions) were created and included in the regression models.

Statistical significance was assessed at .05 alpha level. Proportions of missing on the variables used in the analyses ranged from 0 to $22.9 \%$. The full information maximum likelihood (FIML) estimation is known as a reliable missing data technique providing unbiased estimates of missing parameters in large samples, while retaining natural variability in the data 
[57]; thus, missing data were accommodated using the FIML method [58].

\section{Results \\ Descriptive statistics}

Table 1 displays the descriptive statistics for the complete samples $(N=16,637)$ and the two subgroups (i.e., those with and without chronic health conditions). The mean age of participants was 56.37 years $(S D=$ 18.79 years), and $52.6 \%$ were females. About a quarter of them $(25.8 \%)$ obtained a bachelor or postgraduate degree (e.g., graduate certificate, master and $\mathrm{PhD}$ ). Approximately $30 \%(n=4927)$ of the participants reported that they experienced one or more chronic health condition lasting 6 months or more. Details of the long-term health condition, impairment, and disability are presented in Table 1.

A series of bivariate analyses were conducted to assess differences in socio-demographic characteristics, lifestyle behaviours, social capital measures and self-assessed health status (SF-36) between those with and without chronic health conditions (Table 1). The analyses indicated that those with chronic health conditions were more likely to be female, older and less educated. The summary scores of the SF-36 were significantly lower among those who had chronic health conditions. Compared to those with chronic health conditions, participants who did not have chronic health conditions reported significantly higher level of perceived community cohesion. However, there was no significant difference in the structural social capital (i.e., community participation) between the two subgroups.

\section{Main analysis (multiple linear regression)}

Table 2 presents the results of the first regression analysis (Model I) predicting physical health status (PCS) from the two dimensions of social capital, neighbourhood social climate, lifestyle and socio-demographic factors. As indicated in the Model I, there were no significant interactions of the two components of social capital and chronic health conditions on the physical health status (PCS) at .05 alpha level. In addition, the analysis did not find direct effects of the two dimensions of social capital on PCS. Chronic health conditions were significantly and inversely associated with the outcome variable (PCS) $(\beta=-3.539, S E=.224, p<.001)$.

The second regression analysis (Model II) was carried out to predict MCS using the same set of variables used in the Model I. The regression analysis revealed a significant moderation effect of community participation on the relationship between chronic health conditions and MCS, such that participants with chronic health conditions were more likely to report better mental health status as they engaged more often in the community $(\beta=.652, S E=.249, p=.009)$ (see Fig. 1 for visual summary). While the interaction of perceived cohesion and chronic health conditions had no significant effect on MCS, there was a direct effect of perceived cohesion on the outcome variable, meaning that those who perceived a higher level of cohesion were more likely to report better mental health status $(\beta=.295, S E=.103$, $p=.004)$. Our analysis also indicated that perceptions of disadvantaged neighbourhood environment contributed to poorer mental health status due to the significant and inverse relationship with MCS $(\beta=-.461$, $S E=.144, p=.001)$.

Smoking status and drinking status were found to be significantly associated with MCS (Model II). Compared with those who were obese (BMI $\geq 30$ ), participants who had normal weight were more likely to report better physical health and mental health status. Whereas levels of physical activity were significantly predictive of MCS, those who participated in physical activity at least once in a week reported better status of physical health (PCS) than those who were not participated in physical activity. Some of the socio-demographic factors introduced to the regression models significantly predicted selfreported health status. Gender and age were significantly associated with both PCS and MCS, such that those who were male and younger were more likely to report better status of physical and mental health; however, country of birth did not significantly influence any of the outcome variables.

\section{Discussion}

The current study provided new evidence on the differential effects of the multiple components of social capital (i.e., community participation and perceived cohesion) on the two primary aspects of health status in the Australian adult population. This is an important area of research in public health, given that individual-level health outcomes are determined by social environmental factors including community and neighbourhood characteristics. This study built on prior research demonstrating that social capital is beneficial for a range of health related outcomes and behaviours [19]. Our study shows that the two dimension of social capital can play a crucial role in improving community health and well-being based on the findings on the direct relationships between the two components of social capital and health status. In addition, the study examined the buffering effects of social capital by testing the moderation on the relationship between chronic health conditions and the outcome variables. While a recent study [44] has suggested the modifying effect of social capital on the relationship between disability onset and mental health, the current study reported novel results of the moderation effects of social capital on individuals' health outcomes. 
Table 1 Summary of the univariate and bivariate statistics

\begin{tabular}{|c|c|c|c|c|}
\hline \multirow[t]{2}{*}{ Variables } & $\begin{array}{l}\text { Full } \\
\text { sample }\end{array}$ & $\begin{array}{l}\text { Chronic } \\
\text { condition(s) }\end{array}$ & $\begin{array}{l}\text { No chronic } \\
\text { condition }\end{array}$ & \multirow[t]{2}{*}{$p$-value } \\
\hline & $\mathrm{N}(\%)$ & $\mathrm{N}(\%)$ & N (\%) & \\
\hline \multicolumn{4}{|l|}{ Gender } & 0.004 \\
\hline Male & $7887(47.4)$ & $2252(45.7)$ & $5635(48.1)$ & \\
\hline Female & $8750(52.6)$ & $2675(54.3)$ & $6075(51.9)$ & \\
\hline \multicolumn{4}{|l|}{ Age } & $<0.001$ \\
\hline 18 to 24 & $2333(14.0)$ & $358(7.3)$ & $1975(16.9)$ & \\
\hline 25 to 44 & $5907(35.5)$ & $987(20.0)$ & $4920(42.0)$ & \\
\hline 45 to 64 & $5319(32.0)$ & $1749(35.5)$ & $3570(30.5)$ & \\
\hline 65 and older & $3078(18.5)$ & $1833(37.2)$ & $1245(10.6)$ & \\
\hline \multicolumn{4}{|l|}{ Country of birth } & 0.004 \\
\hline Australia-born & $12,919(77.7)$ & $3756(76.2)$ & $9163(78.3)$ & \\
\hline Foreign-born & $3713(22.3)$ & $1170(23.8)$ & $2543(21.7)$ & \\
\hline \multicolumn{4}{|l|}{ Educational level } & $<0.001$ \\
\hline Year 11 and below & $4187(25.2)$ & $1938(39.4)$ & $2249(19.2)$ & \\
\hline $\begin{array}{l}\text { Year } 12 \text { and } \\
\text { equivalent }\end{array}$ & $2658(16.0)$ & $593(12.1)$ & $2065(17.6)$ & \\
\hline $\begin{array}{l}\text { Diploma and } \\
\text { certificate }\end{array}$ & $5496(33.1)$ & 1566(31.8) & $3930(33.6)$ & \\
\hline Bachelor's and above & $4285(25.8)$ & $822(16.7)$ & $3463(29.6)$ & \\
\hline \multicolumn{4}{|l|}{ Smoking status } & $<0.001$ \\
\hline Yes & $2706(18.4)$ & $906(20.7)$ & $1800(17.4)$ & \\
\hline No & $12,012(81.6)$ & $3473(79.3)$ & $8539(82.6)$ & \\
\hline \multicolumn{4}{|l|}{ Drinking status } & $<0.001$ \\
\hline Yes & $12,097(82.3)$ & $3269(74.7)$ & $8828(85.6)$ & \\
\hline No & $2594(17.7)$ & $1108(25.3)$ & $1486(14.4)$ & \\
\hline \multicolumn{4}{|l|}{ Physical activity (per week) } & $<0.001$ \\
\hline None & 1739 (11.8) & $990(22.4)$ & $749(7.2)$ & \\
\hline 1 to 2 times & $5926(40.1)$ & $1894(38.4)$ & $4232(40.8)$ & \\
\hline 3 to 6 times & $5427(36.7)$ & $1313(29.8)$ & $4114(39.7)$ & \\
\hline Everyday & $1680(11.4)$ & $415(9.4)$ & $1265(12.2)$ & \\
\hline \multicolumn{4}{|l|}{ Body mass index (BMI) } & $<0.001$ \\
\hline Underweight & $308(2.2)$ & $98(2.4)$ & $210(2.1)$ & \\
\hline Normal weight & $5396(38.3)$ & $1210(29.2)$ & $4186(42.1)$ & \\
\hline Overweight & $4970(35.3)$ & $1459(35.2)$ & $3511(35.3)$ & \\
\hline Obese & $3416(24.2)$ & $1374(33.2)$ & $2042(20.5)$ & \\
\hline \multicolumn{2}{|l|}{$\begin{array}{l}\text { Chronic health condition, } \\
\text { impairment and disability }\end{array}$} & N.A. & N.A. & N.A. \\
\hline Sight problem & $469(9.5)$ & & & \\
\hline Hearing problem & $869(17.6)$ & & & \\
\hline Speech problem & $84(1.7)$ & & & \\
\hline $\begin{array}{l}\text { Blackouts, fits or loss } \\
\text { of consciousness }\end{array}$ & $149(3.0)$ & & & \\
\hline Difficulty learning & $247(5.0)$ & & & \\
\hline $\begin{array}{l}\text { Limited use of } \\
\text { arms/fingers }\end{array}$ & $611(12.4)$ & & & \\
\hline $\begin{array}{l}\text { Difficulty gripping } \\
\text { things }\end{array}$ & $559(11.3)$ & & & \\
\hline
\end{tabular}

Table 1 Summary of the univariate and bivariate statistics (Continued)

\begin{tabular}{|c|c|c|c|c|}
\hline \multirow[t]{2}{*}{ Variables } & $\begin{array}{l}\text { Full } \\
\text { sample }\end{array}$ & $\begin{array}{l}\text { Chronic } \\
\text { condition(s) }\end{array}$ & $\begin{array}{l}\text { No chronic } \\
\text { condition }\end{array}$ & $p$-value \\
\hline & N (\%) & N (\%) & N (\%) & \\
\hline $\begin{array}{l}\text { Limited use of } \\
\text { feet/legs }\end{array}$ & $961(19.5)$ & & & \\
\hline $\begin{array}{l}\text { Nervous or emotional } \\
\text { condition }\end{array}$ & $723(14.7)$ & & & \\
\hline $\begin{array}{l}\text { Condition restricting } \\
\text { physical activity }\end{array}$ & $1790(36.3)$ & & & \\
\hline $\begin{array}{l}\text { Disfigurement/ } \\
\text { deformity }\end{array}$ & $102(2.1)$ & & & \\
\hline Mental illness & $400(8.1)$ & & & \\
\hline Shortness of breath & $626(12.7)$ & & & \\
\hline $\begin{array}{l}\text { Chronic or } \\
\text { recurring pain }\end{array}$ & $1329(27.0)$ & & & \\
\hline $\begin{array}{l}\text { Head injury or } \\
\text { other brain damage }\end{array}$ & 209 (4.2) & & & \\
\hline $\begin{array}{l}\text { Long-term condition } \\
\text { still restrictive after } \\
\text { treatment }\end{array}$ & $1403(28.5)$ & & & \\
\hline $\begin{array}{l}\text { Other long-term } \\
\text { conditions }\end{array}$ & $2169(44.0)$ & & & \\
\hline $\begin{array}{l}\text { Physical health } \\
\text { status (PCS) M (SE) }\end{array}$ & $48.24(12.14)$ & 37.42 (13.59) & $52.75(7.94)$ & $<0.001$ \\
\hline $\begin{array}{l}\text { Mental health } \\
\text { status (MCS) M (SE) }\end{array}$ & $49.49(12.25)$ & $42.73(14.14)$ & $52.34(10.09)$ & $<0.001$ \\
\hline $\begin{array}{l}\text { Community } \\
\text { participation M (SE) }\end{array}$ & $2.32(0.81)$ & $2.33(0.84)$ & $2.31(0.80)$ & 0.371 \\
\hline $\begin{array}{l}\text { Perceived community } \\
\text { cohesion } \mathrm{M}(\mathrm{SE})\end{array}$ & $4.66(1.06)$ & $4.61(1.13)$ & $4.68(1.03)$ & 0.001 \\
\hline $\begin{array}{l}\text { Neighbourdhood } \\
\text { social climate M (SE) }\end{array}$ & $2.45(0.69)$ & $2.48(0.73)$ & $2.44(0.70)$ & 0.002 \\
\hline
\end{tabular}

Note. M Mean, SE Standard error

Pearson's Chi-square tests were used for categorical variables, while independent-sample t-tests were used for continuous variables Significance levels for the bivariate analyses (chronic conditions vs. no chronic condition)

In this study, the buffering effect hypothesis was tested with rigorous conceptualisation of the multiple elements of social capital and the longitudinal research design.

Community participation is an indispensable attribute of the structural social capital [13]. Our notable findings showed that the beneficial effects of community participation on mental health were more pronounced among individuals with chronic health condition, impairment or disability. Chronic health conditions are a long-term stressor contributing to poor mental health and quality of life $[59,60]$. Those with chronic health conditions are vulnerable to strains as these health conditions confer difficulties and troubles in many aspects of their life. The increasing prevalence of chronic conditions and comorbidities as well as aging populations have placed a great burden on individuals, communities and health 
Table 2 Multiple linear regression analyses for predictors of self-reported health status (PCS and MCS at Time 2)

\begin{tabular}{|c|c|c|c|c|c|c|}
\hline \multirow[t]{2}{*}{ Parameters } & \multicolumn{3}{|c|}{ DV: PCS $\left(R^{2}=.635\right)$} & \multicolumn{3}{|c|}{ DV: MCS $\left(R^{2}=.515\right)$} \\
\hline & Unst. (St.) & SE & $p$-value & Unst. (St.) & SE & $p$-value \\
\hline \multicolumn{7}{|l|}{ Gender (reference category: Female) } \\
\hline Male & $0.600(0.025)$ & .146 & $<.001$ & $0.771(0.032)$ & .170 & $<.001$ \\
\hline \multicolumn{7}{|l|}{ Age (reference category: 65 and above) } \\
\hline 18 to 24 & $3.239(0.087)$ & .257 & $<.001$ & $-1.938(-0.051)$ & .370 & $<.001$ \\
\hline 25 to 44 & $3.191(0.128)$ & .204 & $<.001$ & $-1.198(-0.047)$ & .282 & $<.001$ \\
\hline 45 to 64 & $1.973(0.080)$ & .191 & $<.001$ & $-0.220(-0.009)$ & .245 & .369 \\
\hline \multicolumn{7}{|l|}{ Country of birth (reference category: Australia-born) } \\
\hline Foreign-born & $0.023(0.001)$ & .177 & .896 & $-0.082(-0.003)$ & .206 & 689 \\
\hline \multicolumn{7}{|l|}{ Education levels (reference category: Year 11 and below) } \\
\hline Year 12 and equivalent & $0.581(0.022)$ & .223 & .009 & $-0.359(-0.013)$ & .252 & .154 \\
\hline Polytechnic diploma and certificate & $0.080(0.003)$ & .213 & .707 & $-0.538(-0.021)$ & .241 & .026 \\
\hline Bachelor degree and above & $0.338(0.010)$ & .255 & .186 & $-0.339(-0.010)$ & .304 & .265 \\
\hline \multicolumn{7}{|l|}{ Smoking status (reference category: No) } \\
\hline Yes & $-0.360(-0.011)$ & .290 & .085 & $-1.222(-0.038)$ & .261 & $<.001$ \\
\hline \multicolumn{7}{|l|}{ Drinking status (reference category: No) } \\
\hline Yes & $0.384(0.012)$ & .212 & .070 & $0.593(0.018)$ & .248 & .017 \\
\hline \multicolumn{7}{|l|}{ Physical activity per week (reference category: None) } \\
\hline $1-2$ times & $1.278(0.053)$ & .286 & $<.001$ & $-0.067(-0.003)$ & .335 & .841 \\
\hline $3-6$ times & $1.473(0.060)$ & .292 & $<.001$ & $0.308(0.012)$ & .341 & .367 \\
\hline Everyday & $1.107(0.030)$ & .349 & .002 & $0.356(0.009)$ & .390 & .361 \\
\hline \multicolumn{7}{|l|}{ BMI (reference category: Obese) } \\
\hline Underweight & $-0.313(-0.004)$ & .614 & .611 & $-0.178(-0.002)$ & .750 & .813 \\
\hline Normal weight & $1.456(0.060)$ & .199 & $<.001$ & $0.484(0.019)$ & .231 & .037 \\
\hline Overweight & $1.095(0.044)$ & .198 & $<.001$ & $0.192(0.008)$ & .228 & .400 \\
\hline Physical health status (PCS at Time 1) & $0.592(0.585)$ & .012 & $<.001$ & $0.117(0.114)$ & .013 & $<.001$ \\
\hline Mental health status (MCS at Time 1) & $0.084(0.083)$ & .010 & $<.001$ & $0.596(0.584)$ & .012 & $<.001$ \\
\hline \multicolumn{7}{|c|}{ Chronic health condition, impairment and disability (reference category: No) } \\
\hline Yes & $-3.539(-0.134)$ & .224 & $<.001$ & $-1.719(-0.064)$ & .254 & $<.001$ \\
\hline Community participation & $-0.009(-0.001)$ & .108 & .933 & $0.153(0.010)$ & .121 & .206 \\
\hline Perceived community cohesion & $0.066(0.006)$ & .088 & .449 & $0.295(0.026)$ & .103 & .004 \\
\hline Neighbourdhood social climate & $-0.020(-0.001)$ & .121 & .872 & $-0.461(-0.026)$ & .144 & .001 \\
\hline Community participation $\times$ chronic health conditions & $-0.270(-0.010)$ & .220 & .219 & $0.652(0.024)$ & .249 & .009 \\
\hline Perceived community cohesion $\times$ chronic health conditions & $0.261(0.013)$ & .170 & .125 & $0.237(0.012)$ & .202 & .240 \\
\hline
\end{tabular}

Note. Unst. Unstandardised regression weight, St. Standardised regression weight, SE Standard error. Gender, age, country of birth, education, smoking status, drinking status, physical activity, BMI, and chronic health conditions are dummy-coded variables

care services in Australia [36, 37]. Based on our findings, it may be crucial to posit a community empowerment approach through integrating health and social services, promoting community partnerships and engagement [61]. Health consequences of stressors depend upon different types and amount of resources available in a community, such as coping, supports and trust [62, 63]. Numerous studies have explored the buffering role of social support as community resources in attenuating negative consequences of external stressors; however less is known about the role and the function of social capital in the stress-buffering process [64]. Therefore, future research is needed to examine underlying mechanisms through which social capital can function as a buffer for the malicious effects of stressors on those who are socially or physically disadvantaged.

The findings also suggest that strong perceptions about communities (i.e., perceived community cohesion) would enable individuals to improve health and wellbeing of community members [29]. Recent studies on 


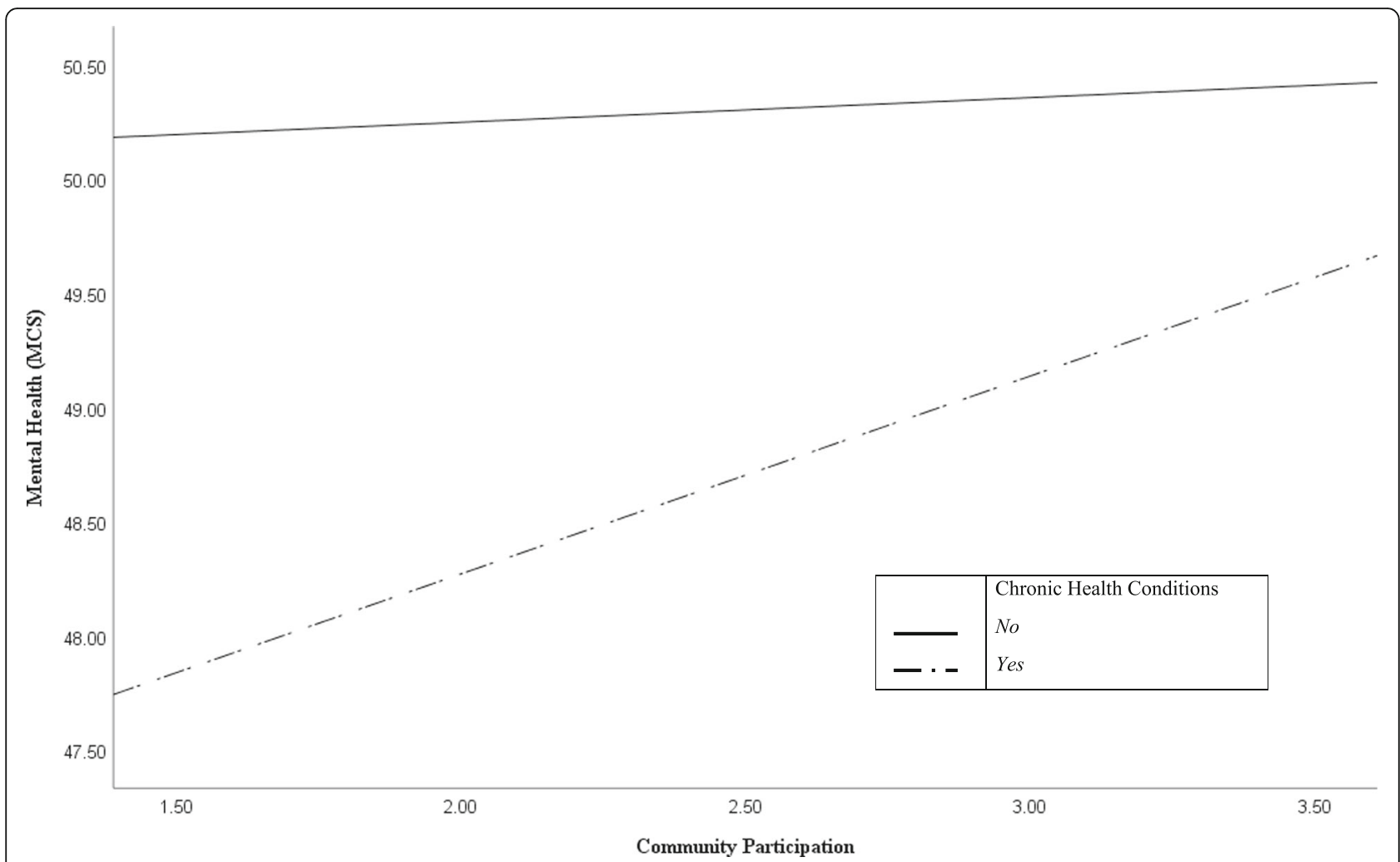

Note. The Process macro was used to visualise moderation by levels of community participation on chronic health conditions and mental health status (MCS). The differential patterns of the relationship (between community participation and MCS) in the chronic condition group and the non-chronic condition group were plotted and compared visually.

Fig. 1 Moderation by levels of community participation on chronic health conditions and mental health status

social capital have indicated that a higher level of perceived cohesion was associated with better mental health $[65,66]$. Consistent with prior evidence, we found the direct effect of the cognitive component of social capital (perceived cohesion) on mental health status, but not on physical health status. A possible explanation is that the pathways from social capital and social relations to mental health are shorter than the pathways to physical health $[43,67]$. This is an area of research that requires further investigation on the effects of perceptions about communities on physical health by testing potential mediators and moderators.

In addition to the effects of social capital, our findings suggest that perceived aspects of neighbourhood climate may be an important determinant of community health and well-being. Previous studies [68-70] have extensively studied the effects of neighbourhood environmental characteristics on various health outcomes, such as life satisfactions and psychological distress. In this study, we found that perceptions of poor quality of neighbourhood environment contributed to worsen mental health among Australian adults. In this regard, building a high quality neighbourhood climate is important to enhance positive perceptions about neighbours and neighbourhoods, which would in turn deliver favorable health and social outcomes. Future interventions may involve local councils and grassroots community organisations to explore and evaluate changes to the composition of the community and neighbourhood settings.

\section{Limitations}

We note some limitations in this study. First, the current study focused on individual-level social capital and did not take into account the influence of ecological and cross-level social capital (e.g., geographic variations in the level of social capital). Future research may utilise a nested study design with clusters of neighbourhoods or communities to assess the impact of the aggregated-level social capital on health related outcomes. Second, there is another line of social capital research that examines social connections and resources emerged within (homogeneity) and between (heterogeneity) groups or communities, namely bonding and bridging social capital [9]. Although this investigation was beyond the scope of the paper, we believe that it is particularly important to explore how different levels or types of social ties/relations (within and between 
groups/communities) could influence health in multicultural and multi-ethnic countries including Australia. Third, this study utilised the two norm-based scores of SF-36 as the primary outcome variables (i.e., PCS and MCS). Given the significant relationships between social capital and mental health, further analyses with the subscales of mental health status (e.g., vitality, roleemotional) would be a useful avenue for future research. Finally, study results may not be generalizable to those persons with illness conditions and disabilities that render them unable to be interviewed and persons with English language difficulties.

In spite of these limitations, findings from this study remain useful in the design of effective community interventions and social policies for the promotion of positive health and behavioural outcomes. In particular, fostering community participation (structural social capital) could be a promising intervention strategy to facilitate better health outcomes in community or neighbourhood settings by attenuating negative consequences of stressors among those with chronic health conditions, impairments or disabilities.

\section{Conclusions}

This study investigated the differential effects of the structural and cognitive social capital on the two forms of health status (physical and mental health) among Australian adults. One of the most notable findings is that community participation (structural social capital) moderated the association between chronic health conditions and mental health status. This suggested that promoting the structural social capital would function as a buffer against the malicious effects of chronic health conditions and disabilities. Specifically, community participation is indispensable to develop an effective community-based program to improve health and well-being of those with chronic health conditions or disabilities, as increasing active participation may generate beneficial effects in this vulnerable population. Subjective perceptions about communities are also a significant factor to improve health outcomes. Consistent with our anticipations, the study found that perceived cohesion was predictive of mental health status. Further research is needed to examine underlying mechanisms linking the multiple dimensions of social capital to health outcomes among individuals who are vulnerable to external stressors.

\section{Abbreviations}

HILDA Survey: Household, Income and Labour Dynamics in Australia Survey; MCS: Mental component score; PCS: Physical component score

\section{Acknowledgments}

This paper utilised confidentialised unit record data from the Household, Income and Labour Dynamics in Australia (HILDA) Survey. The lead author's application for access to datasets of the HILDA Survey General Release was approved by the Australian Data Archive (ADA) on behalf of the data owners, Department of Social Services (Australian Government).

\section{Authors' contributions}

$J \mathrm{KL}, \mathrm{LL}$ and $\mathrm{CM}$ contributed to the study design. JKL conducted the data analysis. JKL and $L L$ drafted the manuscript. All authors revised and approved the final manuscript.

\section{Funding}

This work is supported by the Academic Research Funding (AcRF) Tier 1 Grant from the Ministry of Education, Singapore (PI: Jeong Kyu Lee).

\section{Availability of data and materials}

The data (HILDA Survey General Release) that support the findings of this study are available from the Australian Data Archive (ADA) but restrictions apply to the availability of these data, which were used under license for the study, and so are not publicly available.

\section{Ethics approval and consent to participate}

The National University of Singapore's Institutional Review Board exempted the study from ethics review as the data were de-identified by the Melbourne Institute and the HILDA operations team.

\section{Consent for publication}

Not applicable.

\section{Competing interests}

The authors declare that they have no competing interests.

\section{Author details}

${ }^{1}$ Saw Swee Hock School of Public Health, National University of Singapore and National University Health System, Singapore, Singapore. ${ }^{2}$ School of Psychology, University of Wollongong, Wollongong, Australia.

Received: 7 October 2019 Accepted: 18 February 2020

Published online: 14 March 2020

\section{References}

1. Cohen S. Social relationships and health. Am Psychol. 2004;59(8):676

2. Kawachi I, Berkman L. Social cohesion, social capital, and health. Soc Epidemiol. 2000;174:7.

3. Kawachi I, Subramanian IV, Kim D. Social capital and health. In: Social Capital and Health. New York: Springer; 2008.

4. Murayama H, Fujiwara $Y$, Kawachi I. Social capital and health: a review of prospective multilevel studies. J Epidemiol. 2012;22(3):179.

5. Rocco L, Suhrcke M. Is social capital good for health? A European perspective. Euro Who Int. 2012;1:1-24 Available from: http://www.euro. who.int/_data/assets/pdf_file/0005/170078/Is-Social-Capital-good-for-yourhealth.pdf.

6. Farr J. Social capital: a conceptual history. Political Theory. 2004;32(1):6.

7. Putnam RD. Bowling alone: The collapse and revival of American community. New York: Simon und Schuster, 2001. ISBN. Policy Anal; 2000.

8. Harpham T. Measuring social capital within health surveys: key issues. Health Policy Plan. 2002;17(1):106.

9. Almedom AM. Social capital and mental health: an interdisciplinary review of primary evidence. Soc Sci Med. 2005;61(5):943.

10. Berry H, Rickwood D. Measuring social Capital at the Individual Level: personal social capital, values and psychological distress. J Public Ment Health. 2000;2(3):35.

11. Berry HL, Welsh JA. Social capital and health in Australia: an overview from the household, income and labour dynamics in Australia survey. Soc Sci Med. 2010;70(4):588-96. https://doi.org/10.1016/j.socscimed.2009.10.012.

12. Ding N, Berry HL, O'Brien LV. One-year reciprocal relationship between community participation and mental wellbeing in Australia: a panel analysis. Soc Sci Med. 2015:128:246

13. Shipley M, Berry HL. Longing to Belong: Personal Social Capital and Psychological Distress in an Australian Coastal Region. FaHCSIA Soc Policy Res Pap No 39. 2010; [Cited 2019 Sep 23]; Available from: http://www.ssrn. com/abstract=1703238.

14. Whitley R, McKenzie K. Social capital and psychiatry: review of the literature Harvard Rev Psychiatry. 2005;13(2):71.

15. Berry HL, Rodgers B, Dear KBG. Preliminary development and validation of an Australian community participation questionnaire: types of participation 
and associations with distress in a coastal community. Soc Sci Med. 2007; 64(8):1719.

16. Kawachi I, Kennedy BP, Glass R. Social capital and self-rated health: a contextual analysis. Am J Public Health. 1999;89(8):1187.

17. Maass R, Kloeckner CA, Lindstrøm B, Lillefjell $M$. The impact of neighborhood social capital on life satisfaction and self-rated health: a possible pathway for health promotion? Health Place. 2016;42(October): 120-8. https://doi.org/10.1016/j.healthplace.2016.09.011.

18. Poortinga W. Social relations or social capital? Individual and community health effects of bonding social capital. Soc Sci Med. 2006;63(1):255.

19. Kawachi I, Berkman LF. Social ties and mental health. J Urban Health. 2001; 78(3):458.

20. Kawachi I, Kennedy BP, Lochner K, Prothrow-Stith D. Social capital, income inequality, and mortality. Am J Public Health. 1997;87(9):1491.

21. Lindström M, Hanson BS, Wirfält E, Östergren PO. Socioeconomic differences in the consumption of vegetables, fruit and fruit juices: The influence of psychosocial factors. Eur J Pub Health. 2001;11(1):51.

22. Addy CL, Wilson DK, Kirtland KA, Ainsworth BE, Sharpe P, Kimsey D. Associations of perceived social and physical environmental supports with physical activity and walking behavior. Am J Public Health. 2004;94(3):440-3.

23. Giordano $G N$, Lindström $M$. The impact of social capital on changes in smoking behaviour: a longitudinal cohort study. Eur J Pub Health. 2011; 21(3):347-54.

24. Lindström M, Giordano GN. Changes in social capital and cigarette smoking behavior over time: a population-based panel study of temporal relationships. Nicotine Tob Res. 2016;18(11):2106-2114. Available from: https://academic.oup.com/ntr/article-lookup/doi/10.1093/ntr/ntw120.

25. Lindström M, Moghaddassi M, Merlo J, Bolin K, Lindgren B. Social participation, social capital and daily tobacco smoking: a population-based multilevel analysis in Malmö, Sweden. Scand J Public Health. 2003;31(6):444-50.

26. Rogers EM. Diffusion of innovations. 5th ed. New York: Free Press; 2003. p. 512. Available from: http://books.google.com/books?id=9U1K5 LjUOwEC\&pgis=1.

27. Alesina A, La Ferrara E. Participation in heterogeneous communities. Q J Econ. 2000;115(3):847.

28. Kawachi I, Berkman LF. Neighborhoods and Health: New York: Oxford University Press; 2009. p. 1-352.

29. Yamaguchi A. Influences of social capital on health and well-being from qualitative approach. Global J Health Sci. 2013;5(5):153.

30. Walker RB, Hiller JE. Places and health: a qualitative study to explore how older women living alone perceive the social and physical dimensions of their neighbourhoods. Soc Sci Med. 2007;65(6):1154.

31. Wilkinson RG. Unhealthy societies: The afflictions of inequality. Routledge; 2002. Available from: https://www.taylorfrancis.com/books/9780203421680

32. Kim ES, Kawachi I. Perceived neighborhood social cohesion and preventive healthcare use. Am J Prev Med. 2017;53(2):e35.

33. Echeverría S, Diez-Roux AV, Shea S, Borrell LN, Jackson S. Associations of neighborhood problems and neighborhood social cohesion with mental health and health behaviors: The multi-ethnic study of atherosclerosis. Health Place. 2008;14(4):853.

34. Diez-Roux AV, Mujahid MS, Hirsch JA, Moore K, Moore LV. The impact of neighborhoods on cardiovascular risk: the MESA neighborhood study. Lancet Glob Health. 2016;11(3):353.

35. Australian Institute of Health and Welfare. Chronic disease Overview Australian Institute of Health and Welfare. 2019 [Cited 2019 Sep 23]. Available from: https://www.aihw.gov.au/reports-data/health-conditionsdisability-deaths/chronic-disease/overview.

36. Paez KA, Zhao L, Hwang W. Rising out-of-pocket spending for chronic conditions: a ten-year trend. Health Aff. 2009;28(1):15.

37. Islam MM, Valderas JM, Yen L, Dawda P, Jowsey T, McRae IS. Multimorbidity and comorbidity of chronic diseases among the senior australians: prevalence and patterns. PLoS One. 2014;9(1):e83783.

38. Megari K. Quality of life in chronic disease patients. Health Psychol Res. 2013;1:3.

39. Vancampfort D, Stubbs B, Koyanagi A. Physical chronic conditions, multimorbidity and sedentary behavior amongst middle-aged and older adults in six low- and middle-income countries. Int J Behav Nutr Phys Act. 2017;14(1):147.

40. Campbell C, McLean C. Ethnic identities, social capital and health inequalities: factors shaping African-Caribbean participation in local community networks in the UK. Soc Sci Med. 2002;55(4):643.
41. Fitzpatrick KM, Wright DR, Piko BF, Lagory M. Depressive symptomatology, exposure to violence, and the role of social capital among African American adolescents. Am J Orthop. 2005;75(2):262.

42. Mandelbaum J, Moore S, Silveira PP, Meaney MJ, Levitan RD, Dubé L. Does social capital moderate the association between children's emotional overeating and parental stress? A cross-sectional study of the stressbuffering hypothesis in a sample of mother-child dyads. Soc Sci Med. 2018; 1:112082.

43. Klijs B, Mendes de Leon CF, EUB K, Smidt N. Do social relations buffer the effect of neighborhood deprivation on health-related quality of life? Results from the LifeLines Cohort Study. Health Place. 2017:44:43.

44. Mehbub Anwar AHM, Astell-Burt T, Feng X. Does social capital and a healthier lifestyle increase mental health resilience to disability acquisition? Group-based discrete trajectory mixture models of pre-post longitudinal data. Soc Sci Med. 2019:235:112143.

45. Beaney T, Burrell LM, Castillo RR, Charchar FJ, Cro S, Damasceno A, et al. May measurement month 2018: a pragmatic global screening campaign to raise awareness of blood pressure by the international society of hypertension. Eur Heart J. 2019;40(25):2006.

46. Rashid AA, Devaraj NK. Oh no! now i have diabetes. Rawal Med J. 2018; 43(4):776.

47. Chia Y-C, Ching SM, Chew BN, Devaraj NK, Siti Suhaila MY, Tay CL, et al. May measurement month 2017 blood pressure screening: findings from Malaysia_South-East Asia and Australasia. Eur Hear J Suppl. 2019; 21(Supplement_D):D77.

48. Watson N. M W. The HILDA survey: a case study in the design and development of a successful household panel survey. Longit Life Course Stud. 2012:3:369-81.

49. Wilkins R, Lass I. The household, income and labour dynamics in Australia survey: selected findings from waves 1 to $16 ; 2018$.

50. Summerfield M, Bevitt A, Freidin S, Hahn M, La N, Macalalad N, O'Shea M, Watson N, Wilkins R, Wooden M. HILDA user manual - release 16; 2017.

51. Shields MA, Wheatley Price S, Wooden M. Life satisfaction and the economic and social characteristics of neighbourhoods. J Popul Econ. 2009; 22(2):421.

52. Stafford M, Stansfeld S, Shipley M, Marmot M, Hemingway H. Is the SF-36 a valid measure of change in population health? Results from the Whitehall II study. BMJ. 1997;315(7118):1273.

53. Gandek B, Sinclair SJ, Kosinski M, Ware JE. Psychometric evaluation of the SF-36 ${ }^{\oplus}$ health survey in medicare managed care. Health Care Financ Rev. 2004;25(4):5

54. Australian Bureau of Statistics. National Health Survey: SF36 Population Norms, Australia. Australia: Australian Bureau of Statistics; 1995. [Cited 2019 Sep 23]. Available from: https://www.abs.gov.au/ausstats/abs@.nsf/mf/4399.0.

55. Australian Bureau of Statistics. Australian Health Survey: Updated Results, 2011-2012. [Cited 2020 Jan 23]. Available from: https://www.abs.gov.au/ ausstats/abs@.nsf/Lookup/4364.0.55.003Chapter12011-2012.

56. Muthén L, Muthén B. Mplus user's guide (6th ed). Los Angeles; 2012.

57. Schafer JL, Graham JW. Missing data: our view of the state of the art. Psychol Methods. 2002;7(2):147

58. Graham JW, Cumsille PE, Elek-Fisk E. Research methods in psychology. In: Schinka JA, Velicer WF, editors. Methods of handling missing data. New York: Wiley; 2003. p. 87-114.

59. Pearlin LI. The stress process revisited: reflections on concepts and their interrelationships. In: Handbook of the Sociology of Mental Health; 1999.

60. Thoits PA. Stress and Health: major findings and policy implications. J Health Soc Behav. 2010:51(1 suppl):S41.

61. Haldane V, Chuah FLH, Srivastava A, Singh SR, Koh GCH, Seng CK, et al. Community participation in health services development, implementation, and evaluation: A systematic review of empowerment, health, community, and process outcomes. Maulsby C, editor. PLoS One. 2019;14(5):e0216112 [Cited 2019 Sep 26]. Available from: http://dx.plos.org/10.1371/journal.pone. 0216112.

62. Vassilev I, Band R, Kennedy A, James E, Rogers A. The role of collective efficacy in long-term condition management: a metasynthesis. Health Social Care Community. 2019;27(5):e588.

63. Hibino Y, Takaki J, Ogino K, Kambayashi Y, Hitomi Y, Shibata A, et al. The relationship between social capital and self-rated health in a Japanese population: a multilevel analysis. Environ Health Prev Med. 2012;17(1):44-52 [Cited 2019 Sep 26]; Available from: http://www.ncbi.n/m.nih.gov/ pubmed/21611888. 
64. Saegert S, Carpiano RM. Social support and social capital: A theoretical synthesis using community psychology and community sociology approaches. In: APA handbook of community psychology: Theoretical foundations, core concepts, and emerging challenges; 2017.

65. Berry H, Shipley M. Longing to belong: Social capital and mental health in an Australian coastal community, vol. 39; 2011 .

66. Bassett E, Moore S. Mental Health and social capital: social capital as a promising initiative to improving the mental Health of communities. In: Current Topics in Public Health; 2013.

67. Berkman LF, Glass T, Brissette I, Seeman TE. From social integration to health: Durkheim in the new millennium. Soc Sci Med. 2000;51 (6):843-57.

68. Eibich P, Krekel C, Demuth I, Wagner GG. Associations between neighborhood characteristics, well-being and health vary over the life course. Gerontology. 2016;62(3):362.

69. Brown SC, Mason CA, Spokane AR, Cruza-Guet MC, Lopez B, Szapocznik J. The relationship of neighborhood climate to perceived social support and mental health in older hispanic immigrants in miami, florida. J Aging Health. 2009;21(3):431.

70. Shields M, Wooden M. Investigating the role of neighbourhood characteristics in determining life satisfaction. 2003. Available from: http:// hdl.handle.net/11343/33769.

\section{Publisher's Note}

Springer Nature remains neutral with regard to jurisdictional claims in published maps and institutional affiliations.

Ready to submit your research? Choose BMC and benefit from:

- fast, convenient online submission

- thorough peer review by experienced researchers in your field

- rapid publication on acceptance

- support for research data, including large and complex data types

- gold Open Access which fosters wider collaboration and increased citations

- maximum visibility for your research: over $100 \mathrm{M}$ website views per year

At BMC, research is always in progress.

Learn more biomedcentral.com/submissions 